\title{
NOTAS SOBRE EL EQUIPAMIENTO DEL HOGAR Y EL NIVEL CULTURAL DE LAS FAMILIAS EN EL AMBITO LOCAL
}

311.101

por

\section{Ignacio Ballester Ros}

SUMARIO: I. INTRODUCCION.-II. EL EQUIPAMIENTO DEL HOGAR Y LAS CONDICIONES DE LAS VIVIENDAS: 1. EN EL CONJUNTO NACIONAL, EN LOS AÑOS 1968 y 1975. 2. POR GRUPOS DE MUNicipios. 3. POR REgIONES.-III. LA EVOLUCION DEL NIVEL DE ESTUDIOS ENTRE DOS GENERACIONES, EN EL CONJUNTO NACIONAL, POR GRUPOS DE MUNICIPIOS Y POR REGIONES.

\section{INTRODUCCION}

En el mes de abril de 1975 el Instituto Nacional de Estadística ha llevado a cabo una Encuesta, de alcance nacional, sobre el Equipamiento y Nivel Cultural de las Familias Españolas, extendida a más de 55.000 hogares, en la que se amplía el campo de información de la primera Encuesta, realizada en 1968.

Los resultados, que se refieren a tres campos específicos y diferenciados, se publican en una monografía que comprende cuatro volúmenes. En los dos primeros se presentan las cifras absolutas y los porcentajes relativos al primer campo estudiado: el nivel de vida de las familias en función del grado de equipamiento de sus hogares, las condiciones de comodidad que reúnen sus viviendas y otros aspectos complementarios. El tercer volumen contiene información sobre el segundo campo de investigación: la movilidad 
social intergeneracional bajo el doble aspecto educativo y de la ocupación. En el cuarto volumen, pendiente aún de publicación, se abordará el tercer campo apuntado: el del nivel de vida de los migrantes dentro del territorio nacional y el de la situación educativa y laboral de la mujer casada.

Los resultados se presentan con referencia al conjunto nacional y, en forma muy amplia, por Regiones, por Provincias y por grupos de Municipios.

Las características que se contemplan, referidas al primer campo de estudio, son las que figuran en los cuadros numéricos que se insertan en este comentatrio, si bien aparecen, además, combinadas con la categoría socioeconómica y el nivel de estudios de los cabezas de familia y con el tamaño de los hogares, en función del número de personas que los componen, su discriminación en ancianos, adultos, adolescentes y niños y el predominio de edades que se registra en ellos. Además, dentro de cada Región y Provincia se ofrecen los resultados referidos a las características apuntadas, combinadas también por grupos de Municipios.

Si interesante es el conocimiento del nivel de vida de las familias, no lo es menos el de la movilidad social intergeneracional, que permite apreciar la medida en que una sociedad ofrece oportunidades para que las personas peor dotadas en el aspecto educativo o de empleo puedan ser testigos de cómo sus hijos acceden a estratos sociales superiores, de tal manera que es un indicador claramente representativo del grado de estabilidad social de una comunidad humana.

Los resultados relativos a este segundo campo de investigación se presentan también referidos al conjunto y áreas antes dichas. Se contempla el nivel de estudios de los cabezas de familia en relación con el de sus padres y el de sus hijos de catorce y más años que no estén cursando estudios, en relación con las categorías socioeconómicas de los componentes de los mismos grupos generacionales, si bien la referencia a los hijos se concreta, en este caso, en los activos de catorce y más años. De esta forma puede analizarse la movilidad social entre tres generaciones.

Esta Encuesta es de extraordinario interés en el ámbito nacional, porque da a conocer la estructura del hogar español, e igualmente desde el punto de vista local, por cuanto permite determinar los distintos grados de intensidad de las características estudiadas en las áreas contempladas; pero, dada la abundante infor- 
mación disponible, forzosamente ha habido que limitar la Crónica al análisis y comentario de las características de mayor significación, contenidas en unas tablas simples, elaboradas y referidas exclusivamente a las Regiones y a los grupos de los Municipios, si bien se ofrecen también las cifras nacionales y su evolución de 1968 a 1975, como punto de referencia indispensable para mejor valorar las cifras regionales y municipales expresivas del nivel de vida de las familias.

Queda a disposición de los estudiosos una copiosa información disponible para un examen más profundo y exhaustivo de los resultados de la Encuesta, en especial por lo que hace referencia a las Provincias y al análisis comparativo de las características consideradas en cuanto a las Regiones y grupos de Municipios se refiere.

\section{EL EQUIPAMIENTO DEL HOGAR Y LAS CONDICIONES DE LAS VIVIENDAS}

1. EN El conjunto Nacional, EN Los aÑos 1968 y 1975

La comparación de resultados, en el conjunto nacional, para ciertas características, entre las Encuestas de 1968 y de 1975, resulta aleccionadora y facilita el conocimiento de la evolución registrada en el nivel de vida de las familias, en función de los elementos de que disponen y las condiciones que reúnen los 9.351.937 hogares existentes en 1975.

Los resultados correspondientes, expresados en porcentajes, son éstos :

\begin{tabular}{|c|c|c|}
\hline & 1968 & 1975 \\
\hline $\begin{array}{lllllllllllll}\text { Herencia } & \ldots & \ldots & \ldots & \ldots & \ldots & \ldots & \ldots & \ldots & \ldots & \ldots & \ldots & \ldots \\
\text { Compra } & \ldots & \ldots & \ldots & \ldots & \ldots & \ldots & \ldots & \ldots & \ldots & \ldots & \ldots & \ldots \\
\text { Acceso propiedad } & \ldots & \ldots & \ldots & \ldots & \ldots & \ldots & \ldots & \ldots & \ldots \\
\text { Arrendamiento } & \ldots & \ldots & \ldots & \ldots & \ldots & \ldots & \ldots & \ldots & \ldots & \ldots \\
\text { Otras formas } & \ldots & \ldots & \ldots & \ldots & \ldots & \ldots & \ldots & \ldots & \ldots & \ldots\end{array}$ & $\begin{array}{r}23 \\
25 \\
5 \\
39 \\
8\end{array}$ & $\begin{array}{r}17 \\
39 \\
8 \\
29 \\
7\end{array}$ \\
\hline \multicolumn{3}{|l|}{ Epoca de construcción } \\
\hline 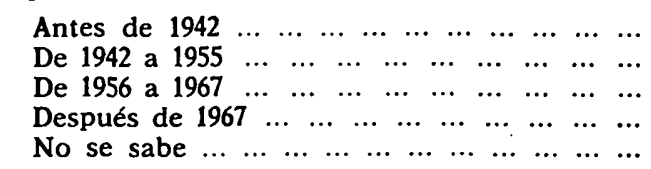 & $\begin{array}{l}70 \\
13 \\
17 \\
- \\
-\end{array}$ & $\begin{array}{r}42 \\
13 \\
25 \\
17 \\
3\end{array}$ \\
\hline \multicolumn{3}{|l|}{ Personas por habitación } \\
\hline 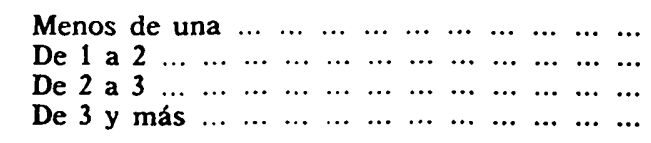 & $\begin{array}{r}62 \\
31 \\
5 \\
2\end{array}$ & $\begin{array}{r}62 \\
34 \\
3 \\
1\end{array}$ \\
\hline
\end{tabular}




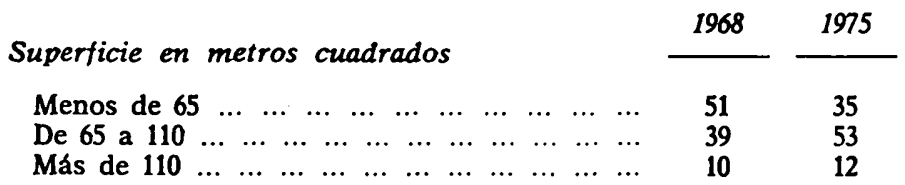

Instalacion de agua corriente

$\begin{array}{llllllllllllllll}\text { No tiene } & \ldots & \ldots & \ldots & \ldots & \ldots & \ldots & \ldots & \ldots & \ldots & \ldots & \ldots & \ldots & 34 & & 13\end{array}$

$\begin{array}{llllllllllllllll}\text { Sólo fría } & \ldots & \ldots & \ldots & \ldots & \ldots & \ldots & \ldots & \ldots & \ldots & \ldots & \ldots & \ldots & 48 & 48 & 37\end{array}$

$\begin{array}{llllllllllllll}\text { Fría y caliente } & \ldots & \ldots & \ldots & \ldots & \ldots & \ldots & \ldots & \ldots & \ldots & \ldots & \ldots & 18 & 18\end{array}$

Instalación de calefacción

$\begin{array}{llllllllllllllll}\text { No tiene } & \ldots & \ldots & \ldots & \ldots & \ldots & \ldots & \ldots & \ldots & \ldots & \ldots & \ldots & \ldots & 94 & 94\end{array}$

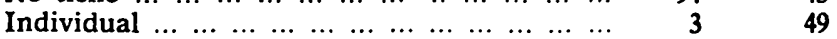

Central $\begin{array}{lllllllllllllllllll} & \ldots & \ldots & \ldots & \ldots & \ldots & \ldots & \ldots & \ldots & \ldots & \ldots & \ldots & \ldots & \ldots & & 3 & & 6\end{array}$

Servicios de aseo e higiene

$\begin{array}{llllllllllllllll}\text { No tiene } & \ldots & \ldots & \ldots & \ldots & \ldots & \ldots & \ldots & \ldots & \ldots & \ldots & \ldots & \ldots & 35 & 17\end{array}$

$\begin{array}{lllllllllllll}\text { Retrete inodoro } & \ldots & \ldots & \ldots & \ldots & \ldots & \ldots & \ldots & \ldots & \ldots & 28 & 11\end{array}$

$\begin{array}{llllllllllllllll}\text { Aseo } & \ldots & \ldots & \ldots & \ldots & \ldots & \ldots & \ldots & \ldots & \ldots & \ldots & \ldots & \ldots & \ldots & \ldots & \ldots \\ \end{array}$

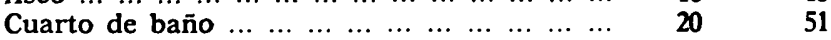

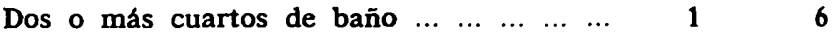

Combustible usado en cocina

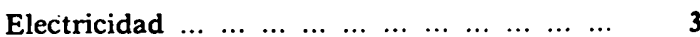

$\begin{array}{lllllllllllllllll}\text { Gas } & \ldots & \ldots & \ldots & \ldots & \ldots & \ldots & \ldots & \ldots & \ldots & \ldots & \ldots & \ldots & \ldots & \ldots & & 58\end{array}$

$\begin{array}{llllllllllllll}\text { Carbón } & \ldots & \ldots & \ldots & \ldots & \ldots & \ldots & \ldots & \ldots & \ldots & \ldots & \ldots & \ldots & \\ \end{array}$

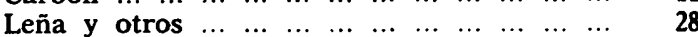

5

81

4

10

Kw. consumidos al mes

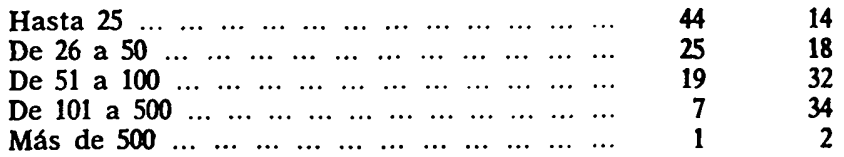

Electrodomésticos, vehículos $\boldsymbol{y}$ otros

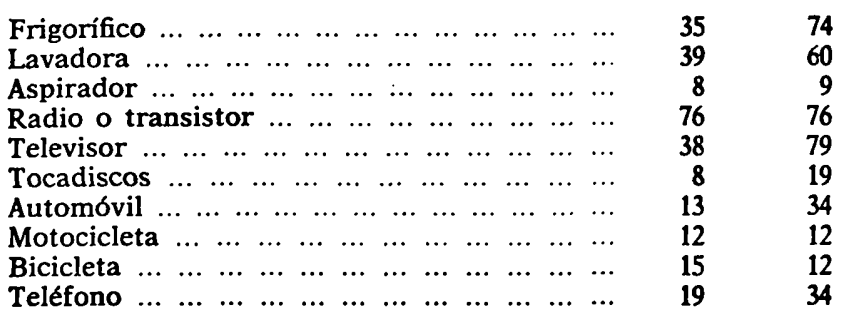

Dias de vacaciones anuales

No ha tenido $\quad \ldots \begin{array}{llllllllllll} & \ldots & \ldots & \ldots & \ldots & \ldots & \ldots & \ldots & \ldots & \ldots & 70 & 63\end{array}$

$\begin{array}{llllllllllllllllll}\text { Hasta } & 20 & \ldots & \ldots & \ldots & \ldots & \ldots & \ldots & \ldots & \ldots & \ldots & \ldots & \ldots & \ldots & 20 & & 15\end{array}$

De 21 a $40 \begin{array}{llllllllllllllll} & \ldots & \ldots & \ldots & \ldots & \ldots & \ldots & \ldots & \ldots & \ldots & \ldots & \ldots & \ldots & 8 & & \end{array}$

Más de $\begin{array}{llllllllllllllllll} & 40 & \ldots & \ldots & \ldots & \ldots & \ldots & \ldots & \ldots & \ldots & \ldots & \ldots & \ldots & \ldots & \ldots & & 2 & \end{array}$ 
Se advierte el fuerte incremento del número de viviendas adquiridas por compra o por otras formas de acceso a la propiedad, que afectan a una vivienda de cada dos y media, y el consiguiente descenso relativo del número de viviendas arrendadas.

Es de destacar la importante renovación del patrimonio inmobiliario urbano, dado que 55 de cada 100 viviendas se hallan ubicadas en edificios construidos o reformados a partir de 1942.

Aumenta la superficie media de las viviendas, y con ello los hogares disponen de mayores espacios para la vida familiar. Ello no altera, sin embargo, de manera sustancial, las disponibilidades de habitaciones por los componentes del hogar. En dos de cada tres viviendas hay menos de una persona por habitación, y en el tercio restante se ubican de una a dos personas por habitación, aunque se apunta una tendencia hacia una mayor holgura.

Se registra igualmente una mejora muy acusada de las disponibilidades de agua corriente y, en especial, de agua caliente en las viviendas. La carencia de agua se reduce, en este período, de la tercera a menos de la sexta parte de las viviendas; y la disponibilidad de agua caliente aumenta de menos de la quinta parte a la mitad de las viviendas.

En cuanto a la calefacción, se reduce a la mitad el número de viviendas que carecen de ella; se duplica el de viviendas con calefacción central, y se generaliza el uso de la calefacción individual, bien con instalaciones fijas o con elementos móviles.

Mejoran notoriamente los servicios de aseo. Se reduce el número de viviendas que no disponen de ellos o los tienen elementales. El cuarto de baño, del que disponían sólo la quinta parte de las viviendas en 1968, se extiende a la mitad de ellas; y en seis viviendas de cada 100 se dispone de dos o más cuartos de baño.

En este período se ha acentuado la generalización en el uso de gas, especialmente el butano, como combustible de cocina, que llega a cuatro de cada cinco hogares; se acentúa la disminución en el consumo de carbón, leña y otros combustibles y continúa extendiéndose paralelamente el consumo de energía eléctrica. En 1968, el 69 por 100 de los hogares consumían menos de 50 kilovatios mensuales, y en 1975 el 68 por 100 consumían más de 50 kilovatios, lo que denota el aumento registrado en el consumo de energía eléctrica para todos los usos del hogar.

Las disponibilidades de aparatos electrodomésticos, de música, televisores, vehículos $\mathrm{y}$ otros elementos se han visto incrementa- 
dos, en conjunto, en un 56 por 100. Cuatro de cada cinco hogares tienen televisor; tres de cada cuatro disponen de frigorifico y de radio o transistor, si bien es evidente que la difusión del televisor ha frenado la de los radiorreceptores; tres de cada cinco hogares disfrutan de lavadora; uno de cada tres, de automóvil y de teléfono, y uno de cada cinco, de tocadiscos. El aspirador ha aumentado muy ligeramente, y el automóvil ha desplazado a la moto y a la bicicleta.

Aún es elevado el número de cabezas de familia que no disfrutan, de hecho, de vacaciones, bien por aceptar su pago en metálico, continuando en el trabajo, o en razón del pluriempleo o dedicación de las vacaciones a otra actividad.

Resulta evidente que se ha producido un cambio fundamental en cuanto a las disponibilidades de viviendas más amplias, adquiridas en propiedad, con instalaciones que garantizan una mayor comodidad y reflejan un mayor bienestar y una elevación del nivel de vida.

\section{POR GRUPOS DE MUNICIPIOS}

Los hogares españoles se distribuyen, por el tamaño de los Municipios, según el Censo de Población de 1970, en esta forma:

\begin{tabular}{|c|c|}
\hline & $\%$ \\
\hline $\begin{array}{llllllllllll}\text { Hasta } 2.000 & \text { habitantes } & \ldots & \ldots & \ldots & \ldots & \ldots & \ldots & \ldots & \ldots & \ldots & \ldots\end{array}$ & 11,7 \\
\hline $\begin{array}{llllllllllllll}\operatorname{De} 2.001 & \text { a } 10.000 & \ldots & \ldots & \ldots & \ldots & \ldots & \ldots & \ldots & \ldots & \ldots & \ldots & \ldots & \ldots\end{array}$ & 21,0 \\
\hline 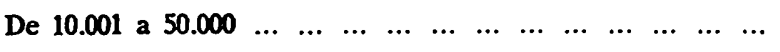 & 21,2 \\
\hline
\end{tabular}

Dos de cada tres hogares se hallan ubicados en zona urbana; uno de cada cinco, en zona intermedia, y uno de cada diez, en zona rural. Se registra un predominio de hogares en Municipios urbanos.

Con arreglo a estos grupos considerados se han elaborado los resultados a nivel de Municipios, referentes al equipamiento del hogar y condiciones de las viviendas en 1975, que presentan este detalle, en el que como término comparativo se consigna, para cada caracteristica y su modalidad, el valor nacional. 


\begin{tabular}{lll}
\hline & M U N I I P I O S \\
\cline { 2 - 4 } & $\begin{array}{c}\text { De hasta } \\
\text { Conjunto más } \\
\text { nacional }\end{array}$ & $\begin{array}{c}2.000 \text { ha- De } 2.001 \text { De } 10.001 \text { de } 50.000 y \\
\text { bitantes a } 10.000 \text { a } 50.000 \text { capitales }\end{array}$ \\
\hline
\end{tabular}

Régimen de tenencia de la Porcentajes de hogares vivienda

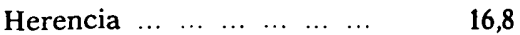

$\begin{array}{llllllllr}\text { Compra } \ldots & \ldots & \ldots & \ldots & \ldots & \ldots & \ldots & 38,9 \\ \text { Acceso propiedad } & \ldots & \ldots & \ldots & & 8,1\end{array}$

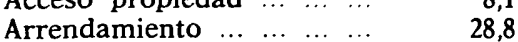

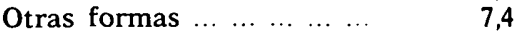

$8 \quad 12,0$

38,9

37,5

1,8

9.8

\section{1,6}

38,4

3,8

16,7

9,5

16,7

42,3

4,5

Epoca de construcción

Antes de 1942 ... $\ldots$...

42,0

De 1942 a 1955

12,8

De 1956 a 1967

25,0

Después de 1967

16,8

No sabe

3,4

72,9
9,3
8,3
7,2
2,3

59,5

11,1

14,1

11,8

8,4

24,5

8,1

38,0

11,5

40,5

Superficie en $\mathbf{m}^{\mathrm{a}}$

Menos de 65

35,4

De 65 a 110

52,3

Más de 110

12,3

35,1

49,2

15,7

34,6

51,3

31,6

37,2

12,7

26,2

19,8

4,1

5,5

Personas por habitación

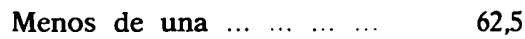

De una a dos $\ldots . . . \quad \ldots . . . \quad 33,9$

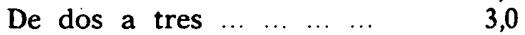

3,0
0,6

67,2

29,9

2,5

De tres y más

\section{0,2}

34,7

4,3

0,8

13,2

37,1

No tiene

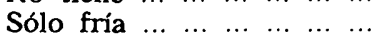

Fría y caliente

49,7

30,4

45,8

24,3

47,1

13,0

41,7

28,5

14,4

33,7

20,2

3,2

\section{Calefacción}

No tiene

Individual:

Móvil

Fija

41,6

72,7

$66,7 \quad 50,4$

27,1

Central

28,6

42,4

51,6

5,6

4,0

5,3

10,4

0,5

0,7

1,9

10,9

Servicios de aseo e higiene

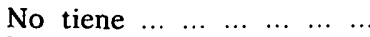

Retrete inodoro ... ... . . . .

Servicios de aseo $\ldots . . . .$.

Cuarto de baño ............

Dos cuartos de baño o aseo.

Más de dos baños o aseos.

14,7

46,5

33,5

14,9

4,3

$11,4 \quad 14,9$

11,4

7,8

51,6

14,6

15,8

16,8

13,2

34,2

53,2

0,7

1,5

65,3

0,7

0,1

0,1

3,5

8,1

$0,2 \quad 1,3$

\section{Combustible usado en cocina}

$\begin{array}{llllll}\text { Electricidad } & \ldots & \ldots & \ldots & \ldots & \ldots\end{array}$

$\begin{array}{lllllllll}\text { Gas } & \ldots & \ldots & \ldots & \ldots & \ldots & \ldots & \ldots & \ldots\end{array}$

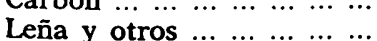




\begin{tabular}{|c|c|c|c|c|c|}
\hline & \multirow[b]{2}{*}{$\begin{array}{c}\text { Conjunto } \\
\text { nacional }\end{array}$} & \multicolumn{4}{|c|}{ MUNICIPIOS } \\
\hline & & $\begin{array}{l}\text { De hasta } \\
2.000 \text { ha- } \\
\text { bitantes }\end{array}$ & $\begin{array}{l}\text { De } 2.001 \\
\text { a } 10.000\end{array}$ & $\begin{array}{c}\text { De } 10.001 \\
\text { a } 50.000\end{array}$ & $\begin{array}{l}\text { De mas } \\
\text { de } 50.000 \text { y } \\
\text { capitales }\end{array}$ \\
\hline
\end{tabular}

Porcentajes de hogares

$K w$. consumidos al mes

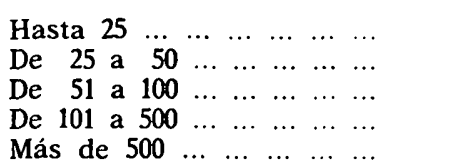

$\begin{array}{rrrrr}13,9 & 34,7 & 24,2 & 11,9 & 4,7 \\ 18,4 & 27,5 & 27,9 & 18,7 & 11,7 \\ 31,9 & 24,7 & 30,5 & 36,4 & 32,2 \\ 34,3 & 12,7 & 17,0 & 32,0 & 48,8 \\ 1,5 & 0,4 & 0,4 & 1,0 & 2,6\end{array}$

\section{Electrodomésticos}

Frigorifico $\ldots \ldots \ldots \ldots \ldots \ldots \quad 73,7$

Lavadora no automática ...

Lavadora automática ......

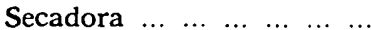

Lavavajillas $\quad \ldots \quad \ldots \quad \ldots \quad \ldots . . .$.

Aspirador

Aparatos de música y TV.

Radio o transistor ... ... ...

$\begin{array}{lllllll}\text { Televisor } & \ldots & \ldots & \ldots & \ldots & \ldots & \ldots\end{array}$

$\begin{array}{llllll}\text { Tocadiscos } & \ldots & \ldots & \ldots & \ldots & \ldots\end{array}$

Magnetófono o cassette

\section{Vehiculos}

Automóvil

Motocicleta

Bicicleta

33,5

12,2

12,4

33,8

19,8

3,0

Proyector, cámara de cine

o tomavistas

\section{Libros}

Menos de 10

De 10 a 50

De 51 a 100

De 101 a 500

Más de 500

76,1

19,1

16,3

49,9

29,4

10,7

2,9

0,3

0,9

53,8

27,8

14,2

3,4

0,5

1,7

71,9

60,0

5,7

69,8

65,9

8,2

8,3

24,0

14,7

24,0

15,6

17,4

12,4

5,4

14,5

0,3

0,7

52,6

29,8

8,9

71,1

22,8

3,6

2,3

6,8

0,2

73,0

35,2

23,5

7,7

1,3

5,2

89,1

32,9

40,6

7,8

4,8

15,6

73,6

80,6

14,5

12,8

81,3

89,9

29,5

24,1

31,1

$18,6 \quad 17,0$

13,5

41,4

6,4

22,1

53,4

$8,6 \quad 15,2 \quad 30,8$

1,5

5,5

$\begin{array}{rrr}67,9 & 58,2 & 38,4 \\ 24,6 & 30,1 & 33,9 \\ 4,8 & 7,3 & 12,8 \\ 2,3 & 3,8 & 11,3 \\ 0,4 & 0,6 & 3,6\end{array}$

Discos o cintas de cassette musicales

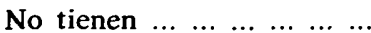

$\begin{array}{lllllll} & \text { Menos de } 10 & \ldots & \ldots & \ldots & \ldots & \ldots\end{array}$

De 10 a 25 ...

De 26 a 50 ...

De 51 a $100 \quad \ldots \quad \ldots \quad \ldots . . .$.

Más de 100

$\begin{array}{llllll}100 & \ldots & \ldots & \ldots & \ldots & \ldots \\ 100 & \ldots & \ldots & \ldots & \ldots & \ldots\end{array}$

73,6

7,4

9,7

5,8

2,6

0,9
90,6

4,1

3,6

1,4

0,2

0,1

\section{6,9}

4,9

78,4

60,9

5,0

2,2

0,7

0,3

$0,3 \quad 1,7$




\begin{tabular}{|c|c|c|c|c|c|}
\hline & \multirow[b]{2}{*}{$\begin{array}{l}\text { Conjunto } \\
\text { nacional }\end{array}$} & \multicolumn{4}{|c|}{ MUNICIPIOS } \\
\hline & & $\begin{array}{l}\text { De hasta } \\
2.000 \text { ha- } \\
\text { bitantes }\end{array}$ & $\begin{array}{l}\text { De } 2.001 \\
\text { a } 10.000\end{array}$ & $\begin{array}{l}\text { De } 10.001 \\
\text { a } 50.000\end{array}$ & $\begin{array}{l}\text { De más } \\
\text { de } 50.000 \text { y } \\
\text { capitales }\end{array}$ \\
\hline & & \multicolumn{4}{|c|}{ Porcentajes de hogares } \\
\hline \multicolumn{6}{|l|}{ Dias de vacaciones anuales } \\
\hline 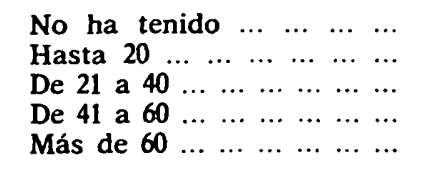 & $\begin{array}{r}62,9 \\
15,1 \\
20,3 \\
0,7 \\
1,0\end{array}$ & $\begin{array}{r}87,8 \\
6,5 \\
4,8 \\
0,3 \\
0,6\end{array}$ & $\begin{array}{r}82,5 \\
8,3 \\
8,3 \\
0,3 \\
0,6\end{array}$ & $\begin{array}{r}67,6 \\
15,3 \\
16,0 \\
0,5 \\
0,6\end{array}$ & $\begin{array}{r}45,3 \\
20,4 \\
31,8 \\
1,1 \\
1,4\end{array}$ \\
\hline Alojamiento en vacaciones & . & & & & \\
\hline 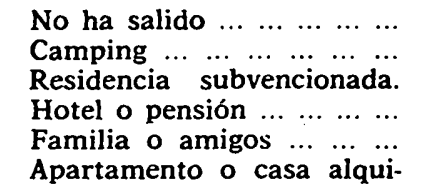 & $\begin{array}{r}42,1 \\
1,7 \\
2,2 \\
9,2 \\
32,2\end{array}$ & $\begin{array}{r}56,9 \\
1,5 \\
2,3 \\
6,6 \\
28,6\end{array}$ & $\begin{array}{r}60,1 \\
1,1 \\
1,6 \\
7,4 \\
24,7\end{array}$ & $\begin{array}{r}51,7 \\
1,0 \\
1,5 \\
7,7 \\
30,6\end{array}$ & $\begin{array}{r}36,0 \\
2,0 \\
2,4 \\
10,0 \\
34,0\end{array}$ \\
\hline 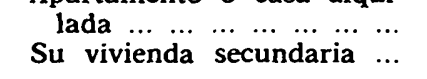 & $\begin{array}{l}6,7 \\
5,9\end{array}$ & $\begin{array}{l}1,7 \\
2,4\end{array}$ & $\begin{array}{l}3,5 \\
1,6\end{array}$ & $\begin{array}{l}4,3 \\
3,2\end{array}$ & $\begin{array}{l}8,1 \\
7,5\end{array}$ \\
\hline $\begin{array}{c}\text { Disposición de vivienda se- } \\
\text { cundaria } \ldots \ldots \ldots \\
\end{array}$ & 7,4 & 5,0 & 5,8 & 5,8 & 9,5 \\
\hline
\end{tabular}

De las cifras anteriores se deduce, en primer término, que la tenencia de vivienda por compra es un fenómeno generalizado en todo el país y a todos los niveles de Municipios. La herencia predomina en la zona rural y pierde valor en la medida en que aumenta el tamaño de los Municipios; por el contrario, el arrendamiento es forma característica de los grandes Municipios y de las capitales, y lo propio ocurre, más acusadamenté, con otras formas de acceso a la propiedad de las viviendas.

En 1975, las viviendas más antiguas se hallan preferentemente situadas en los Municipios de menor peso demográfico. La construcción de nuevas viviendas en el período 1942-1967 se distribuye en razón directa al número de habitantes de los Municipios; mientras que el promedio nacional es, como ya se ha indicado, del 55 por 100, las tasas de nuevas construcciones son del 25 y del 37 para los dos primeros grupos de Municipios, y de 59 y 68 para los dos siguientes, respectivamente, lo que indica que se mantiene un mayor ritmo de construcción en los Municipios de más de 10.000 habitantes, en especial en las capitales y Municipios mayores de 50.000, y que el período 1956-1967 fue, en este orden de cosas, el más importante. 
El aumento de la superficie media de las viviendas es igualmente un fenómeno extendido a los Municipios de todos los niveles, con escasas diferencias entre unos y otros grupos, si bien las superficies mínimas predominan en los Municipios de hasta 10.000 habitantes, en los que, paradójicamente, destacan también las viviendas con superficie mayor, bien antiguas o de nueva construcción en las zonas de influencia de las grandes urbes. Es válida la conclusión fijada con anterioridad respecto al promedio de personas por habitación en las viviendas españolas, aunque es de señalar que el valor de mayor frecuencia, menos de una persona por habitación, sobresale, al propio tiempo, en los grandes y en los pequeños $\mathrm{Mu}$ nicipios; y que la tasa de una a dos personas por habitación se da en los Municipios mayores de 2.000 habitantes, mientras que la de más de dos personas por habitación es más propia de Municipios entre 2.001 a 50.000 habitantes.

La disponibilidad de agua caliente se acrecienta en los Municipios mayores de 10.000 habitantes, y de manera especial en los grandes Municipios y capitales, en los que disfrutan de ella dos de cada tres viviendas. Y la carencia de agua corriente en las viviendas está en razón inversa al volumen demográfico de los Municipios.

Carecen de calefacción por elementos 46 de cada 100 viviendas, situadas principalmente en los Municipios de hasta 50.000 habitantes. Se registra un incremento creciente de disponibilidad de calefacción cón elementos móviles, y con elementos fijos de carácter individual o central, en razón directa del tamaño de los Municipios, afectando la móvil a más de la mitad de las viviendas y la fija a una de cada cinco.

En cuanto a los elementos de aseo e higiene, con la excepción de los grandes Municipios, se of recen todavía altas tasas de carencia o de mera disponibilidad de retrete inodoro, si bien los servicios elementales de aseo se extienden por todo el país, a todos los niveles. El cuarto de baño, como indicador básico del aseo e higiene, predomina en los Municipios mayores de 10.000 habitantes, en los que más de la mitad de las viviendas en ellos ubicadas disponen de él, tasa que se eleva a dos de cada tres en los grandes Municipios y capitales; en los restantes la proporción es menor, de uno por cada cuatro en los rurales y de uno por cada tres en los de la zona intermedia.

El consumo de gas, en especial butano, en cocina se ha generalizado también a todos los niveles; pero, de manera preferente, en 
los grandes Municipios; el de carbón, que se redujo mucho en los últimos años, se mantiene a niveles de consumo casi similares en los Municipios mayores de 2.000 habitantes; la leña y otros combustibles han decrecido muy acusadamente en su consumo en los Municipios mayores de 10.000; y el consumo de electricidad tiende a crecer en los grandes Municipios. Las tasas más elevadas de consumo de energía eléctrica para todos los usos corresponde, como es lógico, a los grandes Municipios, mientras que los consumos más reducidos se mantienen en los Municipios de hasta 10.000 habitantes.

La disponibilidad de aparatos electrodomésticos, de música y televisión, vehículos y otros -téngase en cuenta que la posesión de unos y otros no es incompatible - se incrementa, con carácter general, en razón directa al volumen demográfico de los Municipios; y las tasas más altas corresponden a los mayores de 10.000 habitantes, y muy singularmente a los grandes Municipios y capitales, si bien es de subrayar que la mitad de las viviendas sitas en Municipios de las zonas rural e intermedia disponen de frigorífico, y dos de cada tres de ellas, de televisor; que la lavadora automática ha frenado la disponibilidad de la no automática, y lo propio ocurre al televisor respecto al radiorreceptor. La moto y la bicicleta predominan en los Municipios hasta 50.000 habitantes; en los grandes Municipios y capitales priva el automóvil, que poseen dos de cada cinco hogares, tasa que en las zonas rural e intermedia es de uno por cada cuatro. Es de subrayar que más de la mitad de los hogares de los grandes Municipios y capitales disfrutan de teléfono.

La mitad de los hogares tienen un número muy escaso de libros, y esta escasez se acentúa en los Municipios pequeños y de la zona intermedia; treinta de cada cien disponen de hasta 50 libros; la posesión de libros en cantidades superiores se manifiesta en los grandes Municipios y capitales, en los que se apunta la existencia de pequeñas bibliotecas familiares. En cuanto a los discos o cintas de cassette musicales, casi tres de cuatro hogares no disponen de ellos, si bien su difusión se acentúa en las capitales y grandes Municipios.

El no disfrute de vacaciones anuales por los cabezas de familia es todavía elevado, por las razones expuestas anteriormente, y se extiende a los Municipios de todos los niveles; una tercera parte en el conjunto disfrutan de ellas, si bien en las capitales y grandes 
Municipios esta tasa se eleva a más de la mitad; la duración media de las vacaciones se puede fijar en los treinta días, aunque hay cabezas que disfrutan de vacaciones más prolongadas. Dos de cada cinco disfrutan sus vacaciones sin desplazarse de su domicilio familiar, hecho que se hace más patente en los Municipios hasta 50.000 habitantes. Resalta el hecho de que la tercera parte utilice el alojamiento con familiares o amigos, como forma más generalizada, para los que abandonan temporalmente su domicilio habitual; el hotel o pensión, apartamento o casa alquilada o su vivienda secundaria le siguen en orden de importancia para los cabezas de familia, principalmente en las capitales y grandes Municipios; el camping o la residencia subvencionada ejercen menor atracción.

Resulta evidente, como colofón de los comentarios anteriores, que, en líneas generales, los hogares situados en las capitales y grandes Municipios disfrutan de un grado mayor de bienestar, si bien se advierte una tendencia hacia niveles más altos en los ubicados en los Municipios de menor volumen demográfico. La urbanización del espacio rural alcanza ya a las pequeñas comunidades humanas, y, a plazo medio, las diferencias en el nivel de vida entre las zonas rural, intermedia y urbana tienden a aminorarse de manera muy marcada.

\section{Por Regiones}

Por Regiones, los hogares se distribuyen, en porcentajes, de esta forma:

\begin{tabular}{|c|c|c|c|}
\hline $\begin{array}{lllllllll}\text { Andalucía } & \ldots & \ldots & \ldots & \ldots & \ldots & \ldots & \ldots & \ldots \\
\text { Aragón } & \ldots & \ldots & \ldots & \ldots & \ldots & \ldots & \ldots & \ldots \\
\text { Canarias } & \ldots & \ldots & \ldots & \ldots & \ldots & \ldots & \ldots & \ldots \\
\text { Castilla la } & \text { Nueva } & \ldots & \ldots & \ldots & \ldots & \ldots \\
\text { Castilla la } & \text { Vieja } & \ldots & \ldots & \ldots & \ldots & \ldots \\
\text { Cataluña-Baleares } & \ldots & \ldots & \ldots & \ldots & \ldots & \ldots\end{array}$ & $\begin{array}{r}15,7 \\
3,6 \\
2,9 \\
16,2 \\
6,1 \\
18,1\end{array}$ & 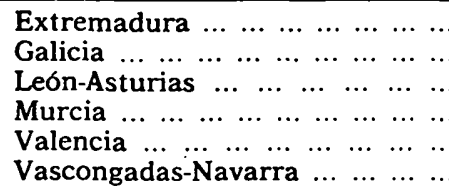 & $\begin{array}{r}3,1 \\
7,5 \\
6,7 \\
3,2 \\
10,0 \\
6,9\end{array}$ \\
\hline
\end{tabular}

De cada tres hogares, uno se halla en la Meseta y dos en la periferia. En Andalucía se ubica casi la sexta parte; en el litoral mediterráneo, casi la tercera parte, y Aragón, Vascongadas y Navarra, Galicia y Canarias acogen a uno de cada cinco hogares.

El detalle de las Regiones con desarrollo análogo al presentado con referencia a los grupos de Municipios, consignando también el valor nacional para las distintas modalidades de cada característica, es el siguiente: 


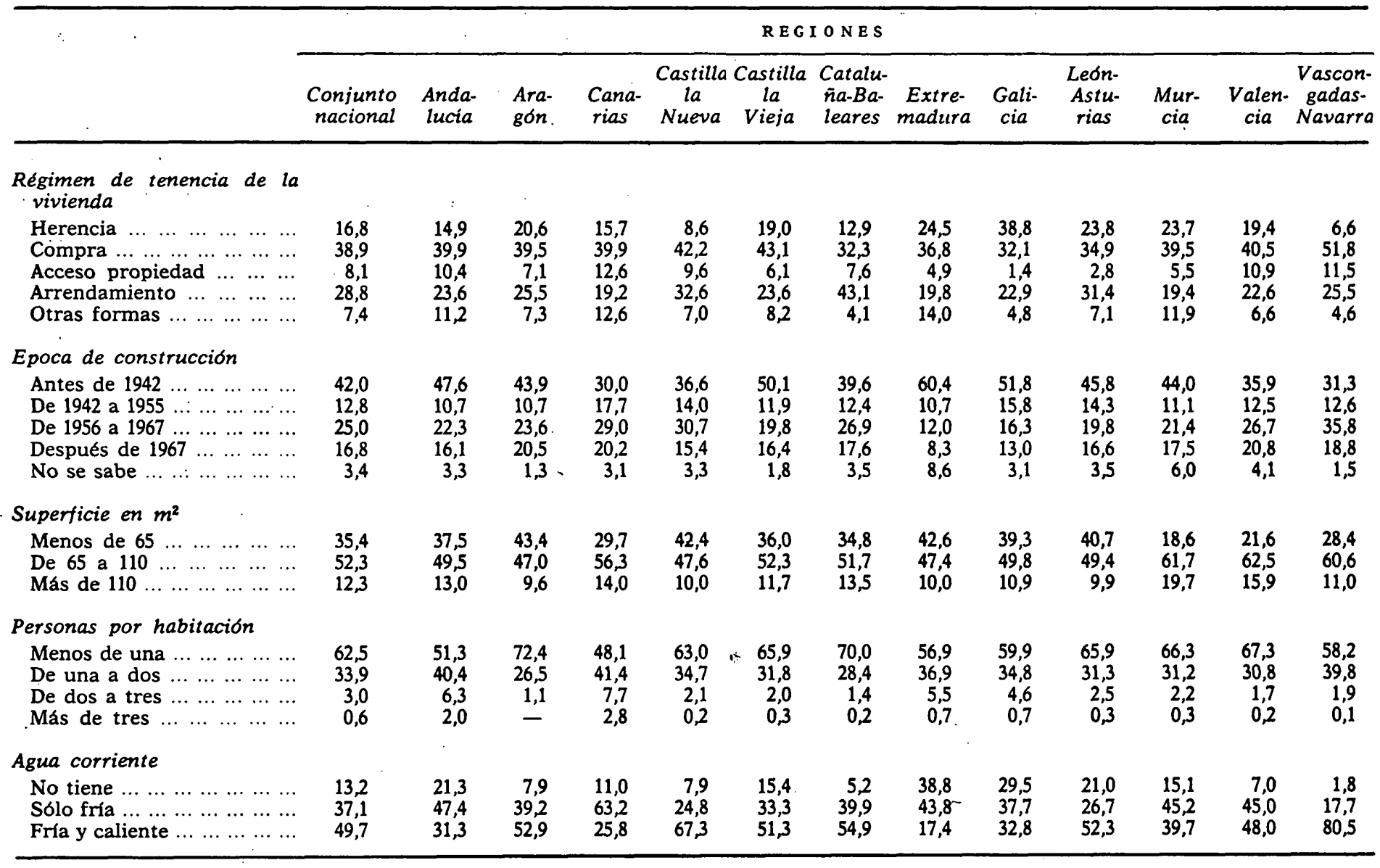




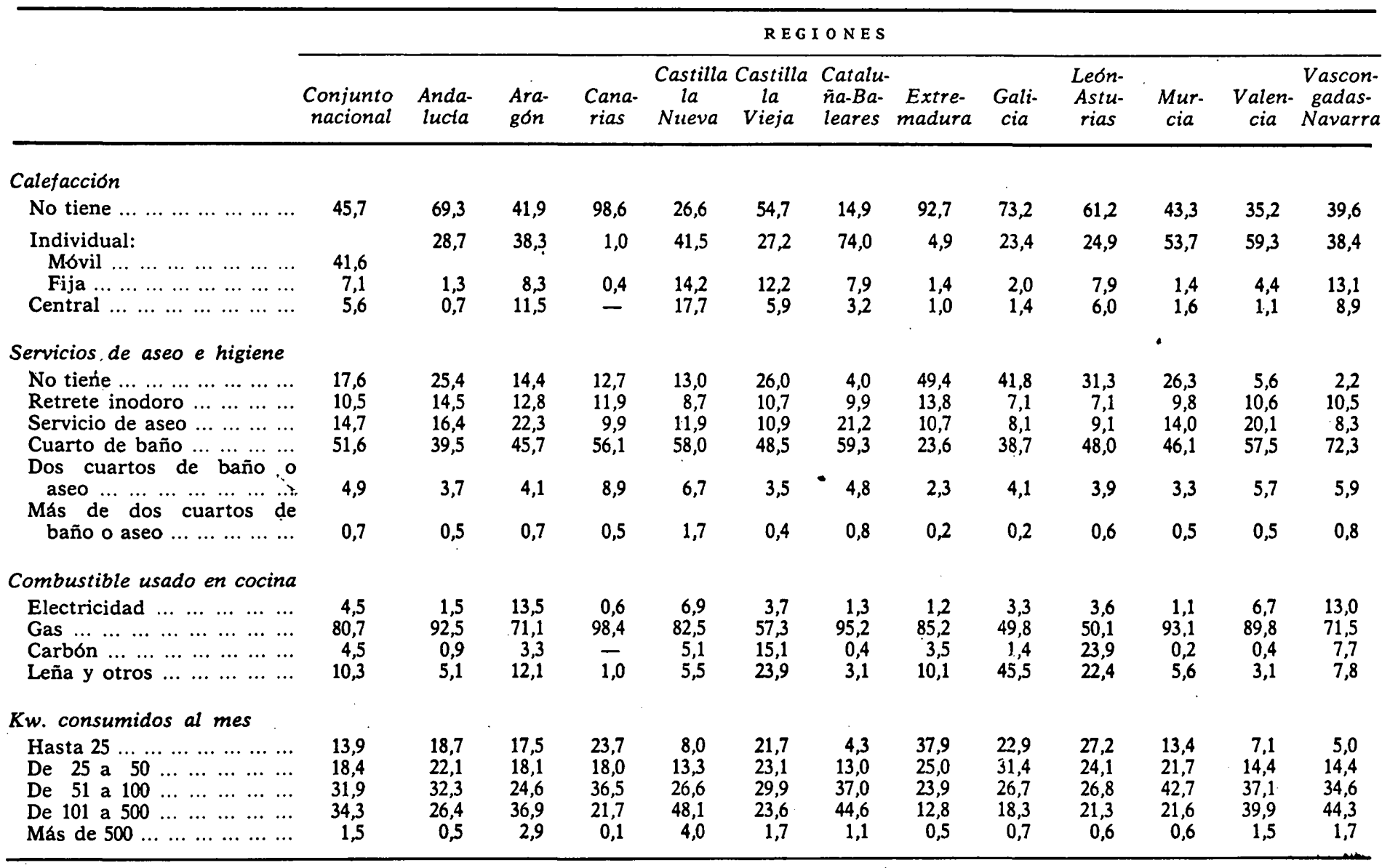




\begin{tabular}{|c|c|c|c|c|c|c|c|c|c|c|c|c|c|}
\hline & \multicolumn{13}{|c|}{ REGIONES } \\
\hline & $\begin{array}{l}\text { Conjunto } \\
\text { nacional }\end{array}$ & $\begin{array}{l}\text { Anda- } \\
\text { lucia }\end{array}$ & $\begin{array}{l}\text { Ara- } \\
\text { gón }\end{array}$ & $\begin{array}{l}\text { Cana- } \\
\text { rias }\end{array}$ & $\begin{array}{l}\text { Castilla } \\
\text { la } \\
\text { Nueva }\end{array}$ & $\begin{array}{l}\text { Castilla } \\
\text { la } \\
\text { Vieja }\end{array}$ & $\begin{array}{l}\text { Catalu. } \\
\text { na-Ba- } \\
\text { leares }\end{array}$ & $\begin{array}{l}\text { Extre- } \\
\text { maditra }\end{array}$ & $\begin{array}{l}\text { Gali- } \\
\text { cia }\end{array}$ & $\begin{array}{l}\text { León- } \\
\text { Astu- } \\
\text { rias. }\end{array}$ & $\underset{\text { Mur. }}{\text { cia }}$ & $\begin{array}{l}\text { Valen- } \\
\text { cia }\end{array}$ & $\begin{array}{l}\text { Vascon- } \\
\text { gadas- } \\
\text { Navaria }\end{array}$ \\
\hline \multicolumn{14}{|l|}{ Electrodomésticos } \\
\hline $\begin{array}{lllllll}\text { Frigorífico } & \ldots & \ldots & \ldots & \ldots & \ldots & \ldots \\
\text { Lavadora no automática } & \ldots \\
\text { Lavadora } & \text { automática } & \ldots & \ldots \\
\text { Secadora } & \ldots & \ldots & \ldots & \ldots & \ldots & \ldots \\
\text { Lavavajillas } & \ldots & \ldots & \ldots & \ldots & \ldots & \ldots \\
\text { Aspirador } & \ldots & \ldots & \ldots & \ldots & \ldots & \ldots \\
\end{array}$ & $\begin{array}{r}73,7 \\
31,9 \\
27,9 \\
6,3 \\
2,6 \\
8,7\end{array}$ & $\begin{array}{r}64,8 \\
36,7 \\
20,8 \\
1,6 \\
1,5 \\
2,5\end{array}$ & $\begin{array}{r}79,6 \\
34,0 \\
27,8 \\
1,2 \\
2,6 \\
6,2\end{array}$ & $\begin{array}{r}53,4 \\
23,9 \\
22,1 \\
0,7 \\
1,0 \\
4,6\end{array}$ & $\begin{array}{r}85,6 \\
34,0 \\
38,5 \\
4,4 \\
4,7 \\
14,8\end{array}$ & $\begin{array}{r}63,2 \\
37,1 \\
24,5 \\
8,9 \\
1,6 \\
8,4\end{array}$ & $\begin{array}{r}92,1 \\
34,1 \\
33,5 \\
3,3 \\
2,8 \\
10,3\end{array}$ & $\begin{array}{r}48,9 \\
23,0 \\
12,0 \\
0,8 \\
1,6 \\
1,5\end{array}$ & $\begin{array}{r}35,9 \\
4,1 \\
14,7 \\
2,3 \\
1,4 \\
5,8\end{array}$ & $\begin{array}{r}51,5 \\
21,4 \\
26,2 \\
. .3,1 \\
2,0 \\
7,0\end{array}$ & $\begin{array}{c}72,1 \\
39,0 \\
18,4 \\
0,3 \\
\frac{-}{3,0}\end{array}$ & $\begin{array}{r}87,4 \\
36,2 \\
26,1 \\
\therefore 2,3 \\
2,8 \\
6,2\end{array}$. & $\begin{array}{r}86,2 \\
43,0 \\
40,6 \\
50,4 \\
3,9 \\
22,5\end{array}$ \\
\hline \multicolumn{14}{|l|}{$\begin{array}{l}\text { Aparatos de música y televi- } \\
\text { sión }\end{array}$} \\
\hline 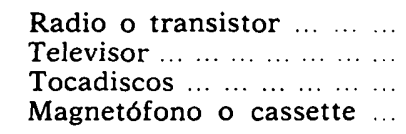 & $\begin{array}{l}76,1 \\
79,4 \\
19,1 \\
16,3\end{array}$ & $\begin{array}{l}72,5 \\
77,5 \\
13,9 \\
11,7\end{array}$ & $\begin{array}{l}79,0 \\
78,3 \\
17,1 \\
17,2\end{array}$ & $\begin{array}{l}82,4 \\
72,5 \\
17,7 \\
14,4\end{array}$ & $\begin{array}{l}82,1 \\
86,9 \\
26,4 \\
21,5\end{array}$ & $\begin{array}{l}75,8 \\
74,4 \\
13,5 \\
12,5\end{array}$ & $\begin{array}{l}77,7 \\
87,9 \\
28,4 \\
21,6\end{array}$ & $\begin{array}{r}66,2 \\
62,1 \\
7,1 \\
8,4\end{array}$ & $\begin{array}{r}70,3 \\
56,6 \\
8,2 \\
7,9\end{array}$ & $\begin{array}{l}76,4 \\
68,6 \\
13,2 \\
12,8\end{array}$ & $\begin{array}{r}71,5 \\
77,2 \\
10,7 \\
9,3\end{array}$ & $\begin{array}{l}70,4 \\
84,3 \\
18,9 \\
17,0\end{array}$ & $\begin{array}{l}83,3 \\
88,5 \\
22,5 \\
22,5\end{array}$ \\
\hline \multicolumn{14}{|l|}{ Vehiculos } \\
\hline $\begin{array}{lllllll}\text { Automóvil } & \ldots & \ldots & \ldots & \ldots & \ldots & \ldots \\
\text { Motocicleta } & \ldots & \ldots & \ldots & \ldots & \ldots & \ldots \\
\text { Bicicleta } & \ldots & \ldots & \ldots & \ldots & \ldots & \ldots\end{array}$ & $\begin{array}{l}33,5 \\
12,2 \\
12,4\end{array}$ & $\begin{array}{r}25,2 \\
16,6 \\
7,6\end{array}$ & $\begin{array}{l}33,0 \\
11,3 \\
14,8\end{array}$ & $\begin{array}{r}33,6 \\
3,0 \\
3,3\end{array}$ & $\begin{array}{r}35,6 \\
7,5 \\
13,2\end{array}$ & $\begin{array}{l}28,5 \\
10,7 \\
18,0\end{array}$ & $\begin{array}{l}44,4 \\
13,0 \\
11,7\end{array}$ & $\begin{array}{l}19,2 \\
13,5 \\
13,7\end{array}$ & $\begin{array}{r}23,4 \\
7,7 \\
7,4\end{array}$ & $\begin{array}{r}27,8 \\
6,1 \\
17,5\end{array}$ & $\begin{array}{l}32,6 \\
26,5 \\
23,1\end{array}$ & $\begin{array}{l}40,6 \\
20,4 \\
14,8\end{array}$ & $\begin{array}{r}36,4 \\
7,9 \\
12,4\end{array}$ \\
\hline \multicolumn{14}{|l|}{ Otros } \\
\hline 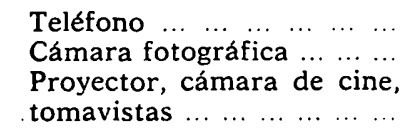 & $\begin{array}{l}33,8 \\
19,8\end{array}$ & $\begin{array}{l}20,5 \\
12,1\end{array}$ & $\begin{array}{l}37,6 \\
19,1\end{array}$ & $\begin{array}{l}29,0 \\
12,7\end{array}$ & $\begin{array}{l}54,5 \\
27,4\end{array}$ & $\begin{array}{l}23,5 \\
14,2\end{array}$ & $\begin{array}{l}44,7 \\
30,1\end{array}$ & $\begin{array}{r}15,4 \\
7,3 \\
0,8\end{array}$ & $\begin{array}{r}18,6 \\
8,5\end{array}$ & $\begin{array}{l}22,5 \\
14,2\end{array}$ & $\begin{array}{l}17,8 \\
10,3\end{array}$ & $\begin{array}{l}29,9 \\
22,4\end{array}$ & $\begin{array}{l}44,1 \\
25,4\end{array}$ \\
\hline \multicolumn{14}{|l|}{ Libros } \\
\hline 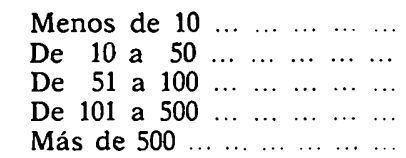 & $\begin{array}{r}52,6 \\
29,8 \\
8,9 \\
6,8 \\
1,9\end{array}$ & $\begin{array}{r}63,6 \\
25,7 \\
6,0 \\
3,6 \\
1,1\end{array}$ & $\begin{array}{r}48,9 \\
34,8 \\
8,3 \\
6,6 \\
1,4\end{array}$ & $\begin{array}{r}55,1 \\
31,6 \\
8,5 \\
4,0 \\
0,8\end{array}$ & $\begin{array}{r}38,9 \\
33,3 \\
12,4 \\
11,6 \\
3,8\end{array}$ & $\begin{array}{r}49,0 \\
33,0 \\
9,5 \\
6,9 \\
1,6\end{array}$ & $\begin{array}{r}49,7 \\
31,0 \\
9,4 \\
7,5 \\
2,4\end{array}$ & $\begin{array}{r}67,2 \\
24,3 \\
4,4 \\
3,6 \\
0,5\end{array}$ & $\begin{array}{r}69,1 \\
20,2 \\
6,0 \\
3,6 \\
1,1\end{array}$ & $\begin{array}{r}53,0 \\
29,1 \\
9,8 \\
6,7 \\
1,4\end{array}$ & $\begin{array}{r}58,3 \\
30,6 \\
6,8 \\
3,8 \\
0,5\end{array}$ & $\begin{array}{r}55,1 \\
28,1 \\
8,7 \\
6,2 \\
1,9\end{array}$ & $\begin{array}{r}41,1 \\
37,5 \\
11,3 \\
8,9 \\
1,2\end{array}$ \\
\hline
\end{tabular}




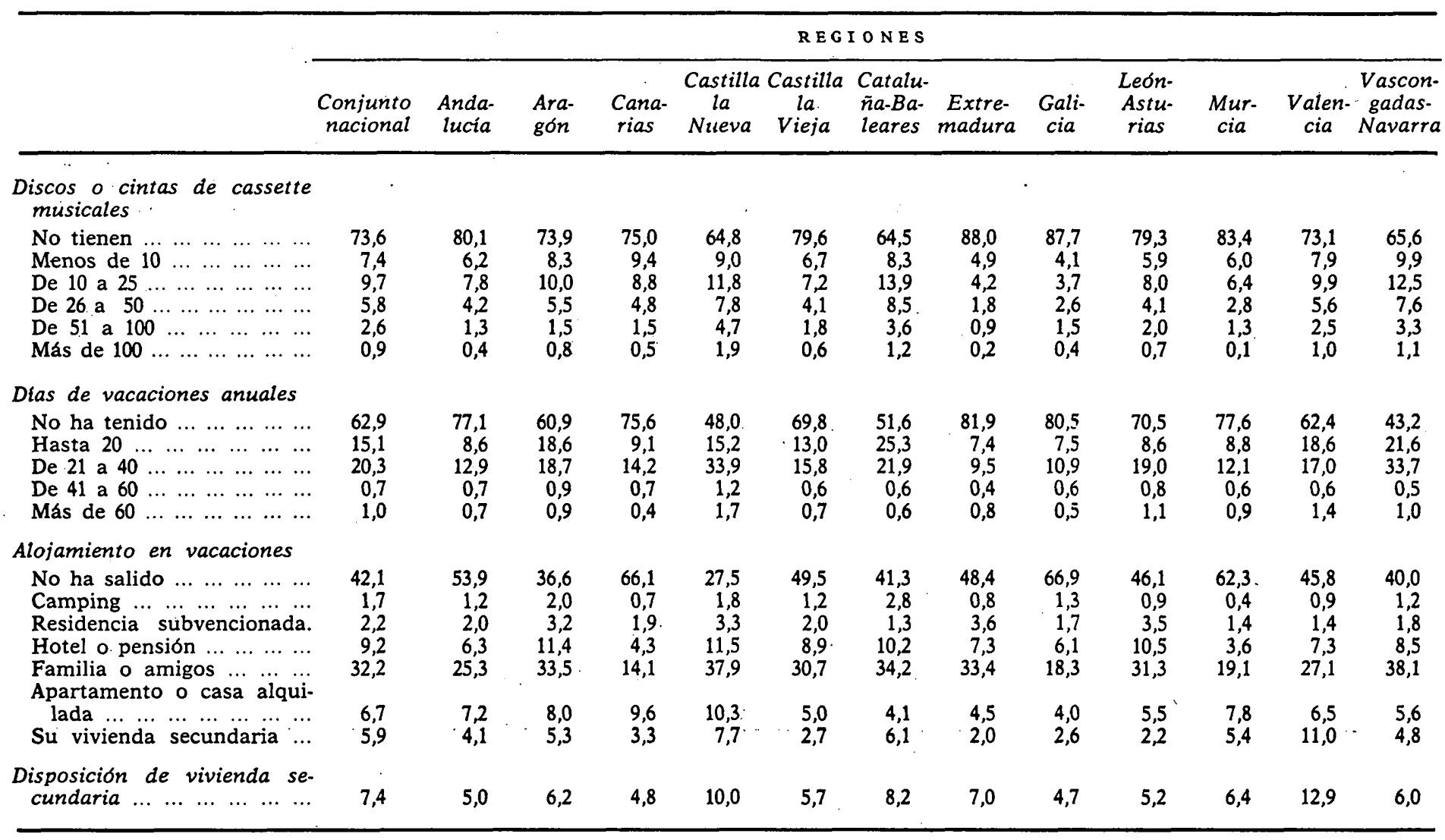


Un somero análisis del cuadro anterior, que subraye las Regiones que, en cada caso, presentan las cifras más significativas respecto al promedio nacional, permite fijar unas conclusiones iniciales de indudable valor.

Considerando aisladamente cada forma de tenencia de las viviendas, se observa que la herencia predomina en dos amplias zonas: la primera, formada por las Regiones de Galicia, Asturias y León, Castilla la Vieja y Extremadura; y la segunda, por las de Aragón, Valencia y Murcia, todas ellas de base originariamente agraria, sin perjuicio de la evolución operada en algunas de ellas hacia el desarrollo industrial; la compra destaca, de una parte, en Castilla la Vieja, Andalucía y Canarias, y de otra, en Vascongadas y Navarra, y también, en coincidencia con el predominio de la herencia, en Castilla la Nueva, Aragón, Valencia y Murcia. Como complemento de la compra se señala la importancia que tienen otras formas de acceso a la propiedad en Andalucía y Canarias, Vascongadas y Navarra, y Valencia; y; finalmente, el arrendamiento sobresale también en Castilla la Nueva y en Cataluña y Baleares.

Las viviendas antiguas, anteriores a 1942, son más numerosas en Galicia, León y Asturias, Castilla la Vieja y Extremadura, así como en Aragón, Murcia y Andalucía. El ritmo de construcción en el período 1942-1967 ha sido más acusado en Castilla la Nueva, Cataluña y Baleares y Vascongadas y Navarra, y también en Aragón y Canarias. La superficie media de las viviendas es más elevada en Castilla la Vieja y Vascongadas y Navarra, Valencia, Murcia y Canarias; las superficies máximas predominan en estas tres últimas Regiones y, además, en Cataluña y Baleares y Andalucía. El mayor número de personas por habitación corresponde a Galicia, Vascongadas y Navarra, Extremadura, Andalucía y Canarias. El patrimonio inmobiliario urbano aparece como de mayor antigüedad al Norte y Oeste de la Península, mientras que las nuevas construcciones se concentran principalmente en el triángulo Cataluña-Baleares, Vascongadas y Navarra y Castilla la Nueva, y además en Canarias. Las viviendas de mayor superficie se sitúan, con preferencia, a lo largo de la zona periférica del litoral mediterráneo, desde Cataluña a Andalucía, y permite intuir, al clima como condicionante.

Por la menor carencia de agua corriente en el hogar destacan: Castilla la Nueva, Cataluña y Baleares, Vascongadas y Navarra, 
Aragón y Valencia; y ellas, juntamente con León y Asturias y Castilla la Vieja, sobresalen por la mayor disponibilidad de agua caliente en el hogar.

La disponibilidad de elementos de calefacción está, en parte, condicionada por el clima. Ambas Castillas, León y Asturias, Vascongadas y Navarra y Aragón destacan en cuanto a la calefacción central; respecto a la individual fija hay que añadir a las citadas a Cataluña y Baleares, que, con Valencia y Murcia, sobresalen también por el mayor uso de elementos móviles.

La disponibilidad de cuarto de baño como indicador, de mayor grado, de los servicios de aseo e higiene afecta básicamente a Castilla la Nueva, Cataluña y Baleares, Vascongadas y Navarra, Valencia y Canarias.

El consumo de carbón en cocina ha quedado reducido, con carácter preferente, a las principales zonas productoras: León y Asturias y Castilla la Vieja. El gas de ciudad, limitado a algunas capitales, y el butano, extendido hasta el área rural, prevalecen en Castilla la Nueva y Extremadura, Cataluña y Baleares, Valencia, Murcia, Andalucía y Canarias. El consumo de energía eléctrica destaca en Castilla la Nueva, Vascongadas y Navarra, y Aragón y Valencia, y los mayores consumos para todos los usos del hogar corresponden a las citadas y a Cataluña y Baleares.

La disponibilidad de aparatos electrodomésticos afecta principalmente a Vascongadas y Navarra, Cataluña y Baleares y Castilla la Nueva, a las que se unen Aragón y Valencia, con respecto a los frigoríficos, y la última, además, por el uso de lavavajillas. Son de señalar las altas tasas de secadoras y aspiradoras en Vascongadas y Navarra.

El radiorreceptor o transistor y el magnetófono sobresalen en Castilla la Nueva, Cataluña y Baleares, Vascongadas y Navarra y Aragón, además de Canarias, con referencia al último elemento citado; pero el tocadiscos se restringe a las tres primeras, y el televisor, más indicativo, a ellas y a Valencia.

El automóvil destaca, en sus valores más altos, en Vascongadas y Navarra, Cataluña y Baleares y Castilla la Nueva, además de Canarias: La motocicleta es de uso más frecuente en Cataluña y Baleares, Andalucía, Valencia y Murcia, y Extremadura; y la bicicleta, además de en las tres últimas citadas, predomina en Vascongadas y Navarra, Aragón, ambas Castillas y León y Asturias. 
El teléfono es elemento predominante en Vascongadas y $\mathrm{Na}$ varra, Cataluña y Baleares y Castilla la Nueva y Aragón; la cámara fotográfica destaca en las tres primeras y en Valencia; y el proyector, en Castilla la Nueva, Cataluña y Baleares y en Valencia y Canarias.

Las mayores disponibilidades de libros, en general, y de pequeñas bibliotecas, así como de discos y cintas de cassette musicales en los hogares, corresponden a Vascongadas y Navarra, Cataluña y Baleares, Castilla la Nueva y Aragón, con la salvedad de que a ellas deben añadirse Castilla la Vieja, en cuanto a libros, y Valencia, respecto a discos y cintas.

Las Regiones en las que los cabezas de familia disfrutan, en mayor proporción, de vacaciones anuales son, en primer término, Vascongadas y Navarra, Cataluña y Baleares y Castilla la Nueva - con el gran peso de la capital de la Nación-, y, a segundo nivel, Valencia y Aragón, que configuran una compacta zona en el cuadrante nordeste de la Península, en el que se hallan las zonas industriales y las urbes más importantes. Con la excepción de Valencia, estas mismas Regiones destacan por disfrutar de vacaciones con desplazamiento del lugar de residencia, alojándose con la familia o los amigos, característica esta última de la que participan también los extremeños. En el uso de vivienda secundaria sobresalen Valencia, y también Cataluña y Baleares y Castilla la Nueva; y las dos últimas utilizan, además, con preferencia, establecimientos hoteleros, juntamente con los de Aragón, y León y Asturias; y Castilla la Nueva utiliza igualmente apartamentos, como los procedentes de Aragón, Murcia, Andalucía y Canarias.

Como resumen de lo expuesto en los párrafos anteriores hay que señalar la existencia del triángulo antes descrito, que cubre el cuadrante nordeste, Vascongadas-Cataluña-Castilla la Nueva, con inclusión, en segundo término, de Aragón y Valencia, como una zona privilegiada en orden al grado de equipamiento del hogar y de condiciones de la vivienda. 


\section{LA EVOLUCION DEL NIVEL DE ESTUDIOS ENTRE DOS GENERACIONES, EN EL CONJUNTO NACIONAL, POR GRUPOS DE MUNICIPIOS .Y POR REGIONES}

Como una muestra del interés que tiene el estudio de la movilidad social intergeneracional, se presentan los resultados, en porcentajes, relativos a la evolución del nivel de estudios entre dos generaciones: la de los cabezas de familia, contemplados en esta Encuesta, y la de sus hijos de catorce y más años que no están cursando estudios, con referencia al conjunto nacional y a los grupos de Municipios.

Al comparar, con referencia al conjunto nacional, ambas magnitudes se observa en los hijos un notable descenso del número de personas analfabetas y sin estudios, el incremento de las que poseen estudios primarios y terminados de los tres ciclos, a excepción de los universitarios, y la disminución de los estudios sin terminar del tercer ciclo, todo ello positivo. Como factor negativo puede calificarse el aumento del número de personas con estudios sin terminar de los dos primeros ciclos.

El examen del detalle referente a los grupos de Municipios considerados permite señalar que, con carácter general, se deducen de él las mismas conclusiones señaladas en el párrafo anterior, con ligeras diferencias poco significativas, que no impiden subrayar el carácter de generalidad con que el fenómeno se produce a todos los niveles de Municipios.

El detalle, en porcentajes, por Regiones es como se indica en las tres páginas siguientes.

Igualmente, los niveles de estudio de los cabezas y sus hijos de catorce y más años que no están cursando estudios, por Regiones, permiten establecer análogas conclusiones a las expuestas, con ligeras diferencias que afectan a Andalucía, Castilla la Nueva, Catataluña-Baleares y Extremadura, pudiendo destacar, una vez más, la uniformidad con que la evolución de los niveles de estudios se ha producido en todo el país. 
MUNICIPIOS

\begin{tabular}{|c|c|c|c|c|c|c|c|c|c|c|}
\hline \multirow[t]{2}{*}{ Nivel de estudios } & \multirow{2}{*}{$\begin{array}{l}\text { Conjunto } \\
\text { Cabeza }\end{array}$} & \multirow{2}{*}{$\begin{array}{l}\text { nacional } \\
\text { Hijos }\end{array}$} & \multicolumn{2}{|c|}{$\begin{array}{c}\text { De hasta } 2.000 \\
\text { habitantes }\end{array}$} & \multicolumn{2}{|c|}{ De $2.001{ }_{10.000}^{a}$} & \multicolumn{2}{|c|}{ De $10.001 a$} & \multicolumn{2}{|c|}{$\begin{array}{c}\text { Más de } 50.000 \\
\text { y Capitales }\end{array}$} \\
\hline & & & Cabeza & Hijos & Cabeza & Hijos & Cabeza & Hijos & Cabeza & Hijos \\
\hline \multicolumn{11}{|c|}{ Porcentajes } \\
\hline $\begin{array}{llllllllll}\text { Analfabetos } & \ldots & \ldots & \ldots & \ldots & \ldots & \ldots & \ldots & \ldots & \ldots \\
\text { Sin estudios } & \ldots & \ldots & \ldots & \ldots & \ldots & \ldots & \ldots & \ldots \\
\text { Estudios primarios } & \ldots & \ldots & \ldots & \ldots & \ldots & \ldots & \ldots\end{array}$ & $\begin{array}{r}8,9 \\
20,6 \\
54,7\end{array}$ & $\begin{array}{r}3,4 \\
11,2 \\
63,7\end{array}$ & $\begin{array}{l}11,1 \\
19,6 \\
65,3\end{array}$ & $\begin{array}{r}2,9 \\
8,1 \\
78,6\end{array}$ & $\begin{array}{l}15,0 \\
28,7 \\
50,4\end{array}$ & $\begin{array}{r}5,1 \\
15,7 \\
67,5\end{array}$ & $\begin{array}{l}11,4 \\
23,8 \\
55,0\end{array}$ & $\begin{array}{r}4,6 \\
14,8 \\
64,0\end{array}$ & $\begin{array}{r}4,2 \\
15,4 \\
53,9\end{array}$ & $\begin{array}{r}1,8 \\
7,3 \\
54,3\end{array}$ \\
\hline \multicolumn{11}{|l|}{ Primer Ciclo: } \\
\hline 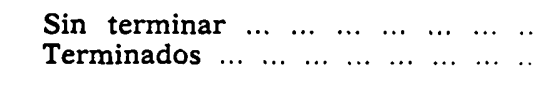 & $\begin{array}{l}1,9 \\
3,6\end{array}$ & $\begin{array}{l}4,6 \\
6,8\end{array}$ & $\begin{array}{l}0,7 \\
0,5\end{array}$ & $\begin{array}{l}2,3 \\
2,9\end{array}$ & $\begin{array}{l}1,4 \\
1,3\end{array}$ & $\begin{array}{l}3,2 \\
3,5\end{array}$ & $\begin{array}{l}1,4 \\
2,6\end{array}$ & $\begin{array}{l}4,6 \\
5,4\end{array}$ & $\begin{array}{l}2,6 \\
5,9\end{array}$ & $\begin{array}{r}6,7 \\
11,6\end{array}$ \\
\hline \multicolumn{11}{|l|}{ Segundo Ciclo: } \\
\hline 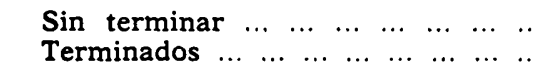 & $\begin{array}{l}0,8 \\
3,3\end{array}$ & $\begin{array}{l}1,0 \\
4,0\end{array}$ & $\begin{array}{l}0,1 \\
0,5\end{array}$ & $\begin{array}{l}0,5 \\
1,9\end{array}$ & $\begin{array}{l}0,2 \\
0,9\end{array}$ & $\begin{array}{l}0,6 \\
1,6\end{array}$ & $\begin{array}{l}0,5 \\
1,9\end{array}$ & $\begin{array}{l}0,8 \\
2,5\end{array}$ & $\begin{array}{l}1,2 \\
5,7\end{array}$ & $\begin{array}{l}1,7 \\
7,4\end{array}$ \\
\hline \multicolumn{11}{|l|}{ Tercer Ciclo: } \\
\hline \multicolumn{11}{|l|}{ No universitarios: } \\
\hline 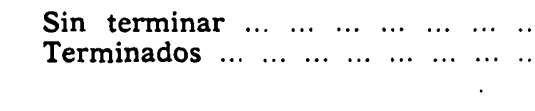 & $\begin{array}{l}0,4 \\
2,2\end{array}$ & $\begin{array}{l}0,2 \\
2,4\end{array}$ & $\begin{array}{l}0,1 \\
0,7\end{array}$ & $\begin{array}{l}0,1 \\
1,5\end{array}$ & $\overline{0,8}$ & $\begin{array}{l}0,2 \\
1,4\end{array}$ & $\begin{array}{l}0,2 \\
1,3\end{array}$ & $\begin{array}{l}0,2 \\
1,7\end{array}$ & $\begin{array}{l}0,6 \\
3,5\end{array}$ & $\begin{array}{l}0,4 \\
3,8\end{array}$ \\
\hline Universitarios: & & & & & & & & & & \\
\hline 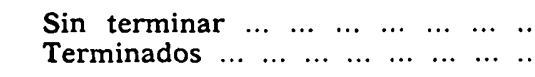 & $\begin{array}{l}0,7 \\
2,9\end{array}$ & $\begin{array}{l}0,2 \\
1,9\end{array}$ & $\begin{array}{l}0,1 \\
0,8\end{array}$ & $\overline{0,8}$ & $\begin{array}{l}0,1 \\
0,6\end{array}$ & $\overline{0,5}$ & $\begin{array}{l}0,2 \\
1,2\end{array}$ & $\begin{array}{l}0,1 \\
0,8\end{array}$ & $\begin{array}{l}1,2 \\
5,3\end{array}$ & $\begin{array}{l}0,4 \\
4,1\end{array}$ \\
\hline
\end{tabular}


REG I O N E S

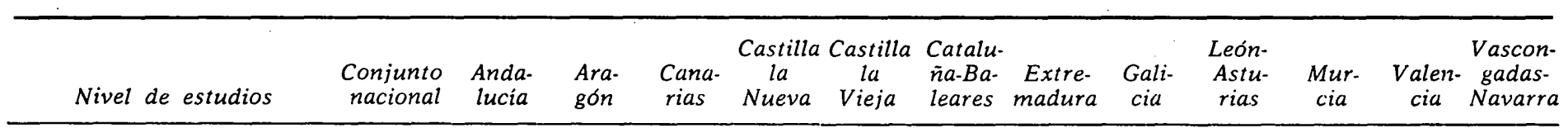

CA B E Z A S

\begin{tabular}{|c|c|c|c|c|c|c|c|c|c|c|c|c|c|}
\hline 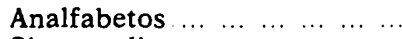 & 8,9 & 16,2 & 6,8 & 18,0 & 6,3 & 4,8 & 5,6 & 19,1 & 11,1 & 4,6 & 13,6 & 8,7 & 3,7 \\
\hline Sin estudios $\ldots \ldots \ldots \ldots$ & 20,6 & 31,3 & 12,7 & 21,9 & 19,0 & 9,3 & 17,3 & 16,2 & 27,4 & 9,9 & 35,6 & 27,8 & 10,0 \\
\hline Estudios primarios $\ldots \ldots \ldots$ & 54,7 & 418 & 653 & 44.5 & 492 & 737 & 578 & 571 & 518 & 731 & 419 & 48.9 & 696 \\
\hline
\end{tabular}

\section{Primer Ciclo:}

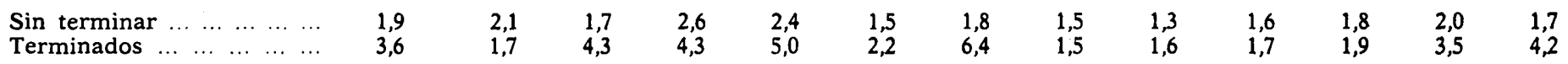

\section{Segundo Ciclo:}

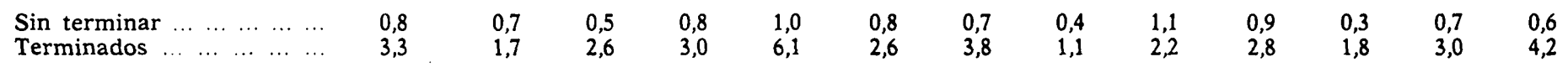

\section{Tercer Ciclo:}

No universitarios:

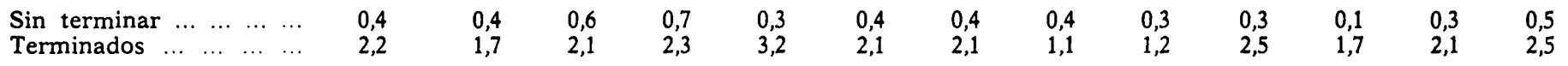

Universitarios:

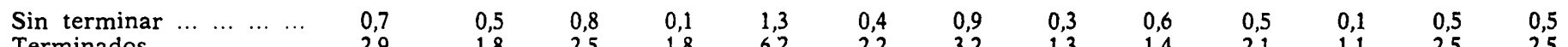

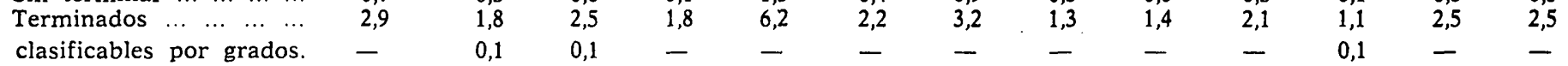




\section{RE G I O NES}

\begin{tabular}{|c|c|c|c|c|c|c|c|c|c|c|c|c|}
\hline Nivel de estudios & $\begin{array}{c}\text { Conjunto } \\
\text { nacional }\end{array}$ & $\begin{array}{l}\text { Anda- } \\
\text { lucia }\end{array}$ & $\begin{array}{l}\text { Ara- } \\
\text { gón }\end{array}$ & $\begin{array}{l}\text { Cana- } \\
\text { rias }\end{array}$ & $\begin{array}{c}\text { Castilla } \\
\text { la } \\
\text { Nueva }\end{array}$ & $\begin{array}{c}\text { Castilla } \\
\text { la } \\
\text { Vieja }\end{array}$ & $\begin{array}{l}\text { Catalu- } \\
\text { na- } B a- \\
\text { leares }\end{array}$ & $\begin{array}{c}\text { Extre- } \\
\text { madura }\end{array}$ & $\begin{array}{l}\text { Gali- } \\
\text { cia }\end{array}$ & $\begin{array}{l}\text { León- } \\
\text { Astu- } \\
\text { rias }\end{array}$ & $\begin{array}{l}\text { Mur- } \\
\text { cia }\end{array}$ & $\begin{array}{l}\text { Valen- } \\
\text { cia }\end{array}$ \\
\hline
\end{tabular}

H I J OS

\begin{tabular}{llllllll} 
Analfabetos & $\ldots$ & $\ldots$ & $\ldots$ & $\ldots$ & $\ldots$ & $\ldots$ & \\
\hline
\end{tabular}

$\begin{array}{llllllll}\text { Sin estudios } & \ldots & \ldots & \ldots & \ldots & \ldots & \ldots & \ldots \\ & & \ldots & \ldots & 11,2\end{array}$

Estudios primarios

\section{7,8
23,8}

$$
\begin{array}{r}
7,8 \\
23,8
\end{array}
$$$$
3,3
$$

1,9
3,3
71,8

5,3
16,4

5,3
57,1

2,3

2,3
8,4
57,6$$
\begin{array}{r}
1,6 \\
2,1 \\
77,4
\end{array}
$$

0,8
5,0
62,5

8,3
10,3
72,2

\section{2,2}

2,2
73,7

1,1
2,3
78,4

5,7
23,8 5,7
23,8
55,2 2,7 13,4 0,9

\section{Primer Ciclo:}

Sin terminar

Terminados

4,6

4,4

4,8

6,8

5,0

4,0

5,2
14,6

2,8
1,5

3,1

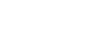

$61,6 \quad 67,0$

Segundo Ciclo:

Sin terminar

Terminados

4,7

0,2
4,0

1,0
3.4

1,3
7.6

1,0
4,0

\section{Tercer Ciclo:}

No universitarios:

\begin{tabular}{|c|c|c|c|c|c|c|c|c|c|c|c|c|c|}
\hline $\begin{array}{lllll}\text { Sin terminar } & \ldots & \ldots & \ldots & \ldots \\
\text { Terminados } & \ldots & \ldots & \ldots & \ldots\end{array}$ & $\begin{array}{l}0,2 \\
2,4\end{array}$ & $\begin{array}{l}0,2 \\
1,8\end{array}$ & $\begin{array}{l}0,2 \\
2,6\end{array}$ & $\begin{array}{l}0,3 \\
3,4\end{array}$ & $\begin{array}{l}0,2 \\
2,9\end{array}$ & $\begin{array}{l}0,2 \\
2,7\end{array}$ & $\begin{array}{l}0,1 \\
2,0\end{array}$ & $\begin{array}{l}0,4 \\
1,3\end{array}$ & $\begin{array}{l}0,4 \\
1,5\end{array}$ & $\begin{array}{l}0,3 \\
2,5\end{array}$ & $\begin{array}{l}0,2 \\
2,0\end{array}$ & $\begin{array}{l}0,2 \\
3,0\end{array}$ & $\begin{array}{l}0,2 \\
3,4\end{array}$ \\
\hline Universitarios: & & & & & & & & & · & & & & \\
\hline $\begin{array}{lllll}\text { Sin terminar } & \ldots & \ldots & \ldots & \ldots \\
\text { Terminados } & \ldots & \ldots & \ldots & \ldots\end{array}$ & $\begin{array}{l}0,2 \\
1,9\end{array}$ & $\begin{array}{l}0,1 \\
1,0\end{array}$ & $\overline{1,8}$ & $\begin{array}{l}0,2 \\
1,0\end{array}$ & $\begin{array}{l}0,9 \\
3,8\end{array}$ & $\begin{array}{l}0,2 \\
1,6\end{array}$ & $\begin{array}{l}0,2 \\
2,5\end{array}$ & $\begin{array}{l}0,1 \\
0,7\end{array}$ & $\begin{array}{l}0,1 \\
1,2\end{array}$ & $\begin{array}{l}0,2 \\
1,7\end{array}$ & $\begin{array}{l}0,1 \\
0,9\end{array}$ & $\begin{array}{l}0,1 \\
2,4\end{array}$ & $\begin{array}{l}0,2 \\
1,7\end{array}$ \\
\hline clasificables por grados. & - & - & - & - & - & - & - & - & - & - & - & - & - \\
\hline
\end{tabular}


REVL-1976, núm. 192. BALLESTER ROS, IGNACIO. NOTAS SOBRE EL EQUIPAMIENTO DEL HOG... REVL-1976, núm. 192. BALLESTER ROS, IGNACIO. NOTAS SOBRE EL EQUIPAMIENTO DEL HOG... 


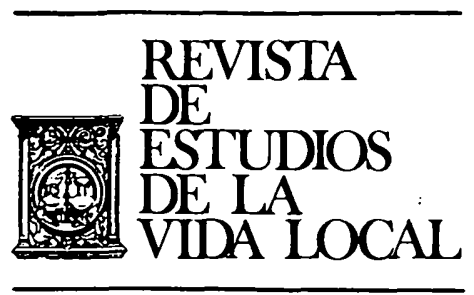

\section{JURISPRUDENCIA}


REVL-1976, núm. 192. BALLESTER ROS, IGNACIO. NOTAS SOBRE EL EQUIPAMIENTO DEL HOG...

REVL-1976, núm. 192. BALLESTER ROS, IGNACIO. NOTAS SOBRE EL EQUIPAMIENTO DEL HOG... 